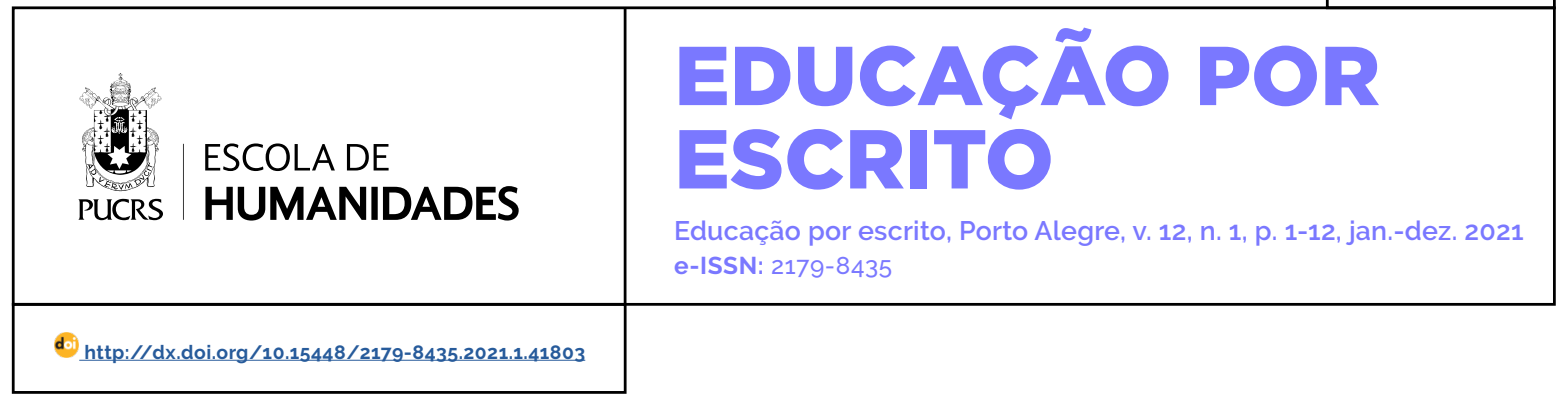

SEÇÃO: A FORMAÇÃO DE PROFESSORES E A EDUCAÇÃO INCLUSIVA: AVANÇOES, DESAFIOS E PERSPECTIVAS

\title{
A influência da formação docente na aprendizagem de estudantes com deficiência intelectual no ensino de química: um estudo de caso
}

The influence of teacher training on the learning of students with intellectual disabilities in chemistry education: a case study

La influencia de la formación del profesorado en el aprendizaje de los alumnos con discapacidad intelectual en la enseñanza de la química: un estudio de caso

\section{Bruna de Oliveira \\ Bonomo ${ }^{1}$}

orcid.org/0000-0001-7955-2008

brunabonomo2019@gmail.com

\section{Ana Nery Furlan \\ Mendes $^{2}$}

orcid.org/0000-0001-6488-5483

ana.n.mendes@ufes.br

Recebido em: 20/09/2021. Aprovado em: 12/11/2021. Publicado em: 17/12/2021.

\section{(c) (i)}

Artigo está licenciado sob forma de uma licença Creative Commons Atribuição 4.0 Internacional.
Resumo: A atuação do professor de química como mediador no processo de ensino aprendizagem para estudantes com deficiência intelectual (DI) exige a utilização de procedimentos didáticos necessários para um bom planejamento da aula. Assim, o presente trabalho tem por finalidade relatar de forma critica e reflexiva uma pesquisa qualitativa, do tipo estudo de caso, desenvolvido em uma escola da rede estadual de ensino, no municipio de São Mateus - ES. Tal pesquisa objetivou analisar a importância da formação docente no processo de ensino aprendizagem de estudantes com deficiência intelectual. Nessa perspectiva, a análise procedeu-se mediante uma entrevista semiestruturada realizada com dois professores da disciplina de química, no ensino médio. Diante dos resultados obtidos neste trabalho, percebemos que há uma precariedade na oferta de formação de professores de química no campo da deficiência intelectual e outras deficiências, mas que apesar disso, existem outros fatores atrelados a formação acadêmica que interferem positivamente no processo de ensino aprendizagem destes estudantes, tais como: proposta pedagógica da escola, trabalho colaborativo, acolhimento com os discentes etc.

Palavras-chave: Ensino de Química. Inclusão. Mediação.

Abstract: The role of the chemistry teacher as a mediator in the teaching process learning for students with intellectual disabilities (DI) requires the use of didactic procedures necessary for a good lesson planning. Thus, the present work aims to report in a critical and reflexive way a qualitative research, of the case study type, developed in a school of the state school, in the city of São Mateus - ES. This research aimed to analyze the importance of teacher education in the teaching process learning students with intellectual disabilities. From this perspective, the analysis was carried out through a semi-structured interview conducted with two chemistry teachers in high school. Given the results obtained in this study, we noticed that there is a precarious ness in the offer of training of chemistry teachers in the field of intellectual disability and other disabilities, but that despite this, there are other factors linked to academic training that positively interfere in the teaching process of learning of these students, such as: pedagogical proposal of the school, collaborative work, with the students etc.

Keywords: Chemistry teaching. Inclusion. Mediation.

Resumen: El papel del profesor de química como mediador en el proceso de aprendizaje de enseñanza para estudiantes con discapacidad intelectual (DI) requiere el uso de procedimientos didácticos necesarios para una buena planificación de la lección. Por lo tanto, el presente trabajo tiene como objetivo informar de manera crítica y reflexiva una investigación cualitativa, del tipo estudio de caso, desarrollada en una escuela de la escuela estatal, en la ciudad de São 
Mateus - ES. Esta investigación tuvo como objetivo analizar la importancia de la formación docente en el proceso de enseñanza de los estudiantes con discapacidad intelectual. Desde esta perspectiva, el análisis se realizó a través de una entrevista semiestructurada realizada a dos profesores de química en la escuela secundaria. Diante dos resultados obtidos neste trabatho, percebemos que há uma precariedade na oferta de formação de professores de química no campo da deficiência intelectual e outras deficiências, mas que apesar disso, existem outros fatores atrelados a formação acadêmica que interferem positivamente no processo de ensino aprendizagem destes estudantes, tais como: proposta pedagógica da escola, trabalho colaborativo, acolhimento com os discentes etc.

Palavras-chave: Enseñanza de la química. Inclusión. Mediación.

\section{Introdução}

Este artigo é produto da dissertação de mestrado intitulada As práticas pedagógicas e a deficiência intelectual no ensino de química: desafios e possibilidades no contexto escolar, em que se apresenta um recorte do estudo de caso, a partir dos resultados de uma entrevista semiestruturada realizada com dois professores de química, que atuam no ensino médio, em turmas com estudantes com deficiência intelectual. O objetivo deste estudo foi de contribuir com a reflexão sobre a importância da formação docente no processo de ensino aprendizagem, sobretudo para atender a diversidade encontrada nas escolas e atuar na perspectiva de uma educação inclusiva na sala de aula.

O processo de escolarização das pessoas com deficiência é marcado por uma trajetória histórica de lutas na busca do seu direito ao acesso a rede regular de ensino e o alcance da aprendizagem com qualidade. Observamos que as matrículas de estudantes com deficiência em escolas regulares vêm crescendo a cada ano em todas as modalidades de ensino no país. No ano de 2019 . no Brasil, as matrículas da educação especial, na etapa do ensino médio, alcançaram o total de 126.029 estudantes (INSTITUTO NACIONAL DE ESTUDOS E PESQUISAS EDUCACIONAIS ANISIO TEIXEIRA, 2019). Quando é avaliada a diferença no número de matrículas entre 2015 e 2019, por etapa de ensino, percebe-se que as matriculas no Ensino médio cresceram 91,9\% (INEP/MEC, 2019).
Considerando o crescimento no número de matriculas, aumenta a exigência por um fazer pedagógico que atenda este contexto de diversidade, onde é preciso discutir sobre a garantia de investimentos públicos destinados para a educação especial, tendo em vista melhorias das condições de ensino-aprendizagem, formação/valorização de professores e políticas públicas voltadas para a assistência das pessoas com deficiência em todas as dimensões humanas (BRASIL, 2007).

\section{O ensino de química e a deficiência intelectual: um currículo de abordagem inclusiva}

Um professor que aspira ter uma boa didática necessita aprender a cada dia como lidar com a subjetividade do aluno, sua linguagem, suas percepções e sua prática de ensino. Sem essas condições o professor será incapaz de elaborar problemas, desafios, perguntas relacionadas com os conteúdos, pois essas são as condições para que haja uma aprendizagem significativa. No entanto, para que o professor atinja efetivamente seus objetivos, é preciso que ele saiba realizar vários processos didáticos coordenados entre si, tais como o planejamento, a direção do ensino da aprendizagem e da avaliação (LIBÂNEO, 1994).

Nesta perspectiva, a disciplina de química pretende oportunizar aos estudantes do ensino médio, acesso ao conhecimento químico de modo que este proporcione experiências aos estudantes que promovam sua inclusão na sociedade moderna e tecnológica, ampliando sua capacidade de refletir e agir na sua própria realidade. Este ideal vai ao encontro ao Currículo Básico Comum do estado do Espírito Santo, que diz "um currículo de abordagem inclusiva é considerar os diferentes espaços tempos da escola como essenciais no processo de ressignificação das práticas educativas" (SECRETARIA DE EDUCAÇÃO DO ESTADO DO ESPIRITO SANTO, 2009, p. 39).

Schnetzler (2004) corrobora com esta ideia afirmando que a escola é uma instituição social que auxilia, através da mediação docente, para que os alunos possam ter acesso e se apropriar 
de conhecimentos que são construidos historicamente pela cultura humana - conhecimentos científicos/químicos - que contribuem leituras críticas do mundo no qual estão inseridos.

Maldaner (2006, p. 165) defende que.

Dentro de uma concepção histórico-cultural de ensino e aprendizagem, de estudante e professor, de matéria e currículo, é possivel melhorar, sensivelmente, o nivel do conhecimento químico aprendido na escola. Para isso temos de superar a posição tradicional das propostas de ensino de química que colocam todo o esforço do trabalho escolar em torno dos conteúdos descontextualizados, segundo uma lógica do conhecimento sistematizado que é adequada, apenas, para quem já conhece Química [...].

Cunha (2012, p. 140) afirma ainda que,

As condições de inclusão alicerçam-se, também, na forma de construir o currículo escolar, na forma de olhar a escola, o estudante e o professor. Mas, há um longo caminho a seguir, pois a grande maioria dos educadores, provavelmente, ainda está condicionada a práticas de ensino provenientes das tendências pedagógicas que foram incorporadas ao senso comum, em razão do modelo que predominou na educação por muitos anos. A forma de ensinar e também a forma que se aprendeu nos bancos escolares durante os anos em que o docente de hoje era o discente de ontem. Essa maneira de aprender e de ensinar, que é transmitida de geração em geração, no entanto, não dá mais conta da diversidade que há nas salas de aula.

Quando refletimos sobre as condições que a educação inclusiva se alicerça também percebemos que é necessário repensar sobre a formação inicial dos professores de química e outros processos formativos já vivenciados, haja vista que estas não dão conta mais de atender os estudantes que atualmente nos deparamos nas salas de aula. É preciso ressignificar a construção do currículo com base nos conhecimentos dos estudantes, para que tenha sentido para os mesmos, e isso se contrapõe com tendências pedagógicas tradicionais incorporadas ao longo do tempo (BITENCOURT; ARAÚJO, 2014).

\section{O processo de mediação e a importância da formação docente}

Partindo desse pressuposto, a mediação adquire um caráter de grande importância, uma vez que abrange três questões imprescindiveis ao processo de construção do conhecimento: "o aluno, como o sujeito que aprende; o professor como mediador; a cultura, os signos como ferramentas a serem empregadas. O princípio que regula a dinâmica implícita nessa trama conceitual é a interação social" (VYGOTSKY, 1987, p. 161).

Berni (2006, p. 2539), defende o processo de mediação afirmando que: "É aqui que está a fundamental responsabilidade dos educadores no ambiente escolar: o desenvolvimento dos alunos através da aprendizagem que vai se dar pela mediação".

Vygotsky (1995, p. 50) trata do assunto em seus estudos e confirma que,

Há uma relação de dependência entre o de-
senvolvimento do ser humano e o aprendizado
realizado num determinado grupo social e que
a construção de conhecimentos se dá pela
inclusão do sujeito com o meio e com o objeto
de estudo, e nessa perspectiva o professor vai
mediar essa relação e favorecer a interação,
pois o professor é uma ferramenta essencial
para que haja o desenvolvimento dos potenciais
que o aluno poderá desenvolver.

Na atualidade, não é mais possivel se falar em barreiras cognitivas, no sentido de impedimento absoluto, limite estático ou fronteira objetiva para o aprendizado, no que se refere ao estudante com deficiência intelectual, da forma como se afirmou por muito tempo, a partir de concepções educacionais tradicionais, com inspirações positivistas, cartesianas, ou do "modelo médico da deficiência" (BRASIL, 2008).

Embora a química seja uma disciplina que traz desafios para muitos estudantes, ao se discutir sobre as práticas pedagógicas no ensino de química se faz necessário que o professor se coloque na condição constante de busca de conhecimentos e a partir da realidade vivenciada em sala de aula, possa ser o grande mediador para que o estudante com deficiência intelectual consiga compreender e adquirir o conhecimento desenvolvido no campo educacional.

As práticas pedagógicas precisam ser entendidas em uma visão de totalidade na medida que as relações dialéticas se estruturam e pautam nas mediações entre o global e o particular. Franco 
(2012), defende que as práticas pedagógicas são práticas sociais que se organizam para dar conta de determinadas expectativas educacionais de um grupo social, onde dois aspectos tornam-se relevantes: a articulação com as expectativas do grupo e existência de um coletivo.

Para Cury (2014), as práticas pedagógicas tornam-se valioso instrumento para a garantia do direito à educação de todos que acessam à escola. Para tanto, precisa ser pensada a partir da constituição humana naquele ambiente, considerando as diferenças existentes e tomando, como ponto de partida para a ação pedagógica, as especificidades presentes. Desse modo, o professor, ao planejar, procura reduzir ou remover os obstáculos impeditivos da aprendizagem dos estudantes, em uma ação pensada numa lógica potencializada dos sujeitos envolvidos, buscando promover a aprendizagem para todos.

A formação de professores deve estar incorporada ao cotidiano escolar de modo que estes profissionais tenham entusiasmo e acreditem que é possível inovar suas práticas pedagógicas a partir de experiências vividas com sucesso na utilização de recursos alternativos.

Segundo Rodrigues (2017, p. 35).

A formação de professores é um mecanismo estratégico das sociedades contemporâneas para procurar atingir os objetivos educacionais mais ambiciosos e mais consentâneos com as exigências que são priorizadas pelos diferentes governos. Ela é assim concebida como uma 'janela de oportunidade' para desencadear, apoiar, supervisionar e avaliar mudanças na educação.

Corroboramos com o posicionamento de Pimenta (1997, p. 5) quando diz que:

Contrapondo-me a essa corrente de desvalorização profissional do professor e às concepções que o consideram como simples técnico reprodutor de conhecimentos e/ou monitor de programas pré-estabelecido, tenho investido na formação de professores, entendendo que na sociedade contemporânea cada vez mais se torna necessário o seu trabalho enquanto mediação nos processos constitutivos da cidadania dos alunos, para o que concorre a superação do fracasso e das desigualdades escolares. O que, me parece, impõe a necessidade de repensar a formação de professores
Pensando nessas questões, precisamos ampliar as reflexões voltadas para a ampliação de investimentos públicos na política de formação de professores, uma vez que mesmo inseridos em uma sociedade com tantos avanços tecnológicos e científicos, este profissional continua representando sua relevância no processo de mediação da aprendizagem dos estudantes, com ou sem deficiência.

\section{Percurso metodológico}

Quanto a sua abordagem, caracteriza-se como um estudo qualitativo por se preocupar com o aprofundamento em questões subjetivas do fenômeno estudado e dos elementos que o compõem. Segundo André (2013, p. 97),

As abordagens qualitativas de pesquisa se fundamentam em uma perspectiva que concebe o conhecimento como um processo socialmente construido pelos sujeitos nas suas interações cotidianas, enquanto atuam na realidade, transformando-a e sendo por ela transformada.

A presente pesquisa é um estudo de caso, que devido aos seus procedimentos, vem possibilitar ao pesquisador a oportunidade de explicar, de explorar ou descrever fenômenos atuais que acontecem em um dado contexto.

Malheiros (2011, p. 94) descreve que o estudo de caso,

Consiste em se pesquisar uma situação especifi-
ca para compreender uma determinada relação
de causa e efeito. Para isso, observa-se que o
resultado obtido considerando uma variável
especifica implantada no evento com ou sem
intenção. Os estudos de caso têm seu espaço
de atuação quanto à pesquisa fortemente de-
limitados, assim como há sólida delimitação
do tempo.

Considerando a caracterização da pesquisa, pretendemos a partir do método dialético, conhecer e compreender os elementos preciosos encontrados no cotidiano escolar, tendo em vista a problematização proposta. Para Vygotsky "estudar algo historicamente significa estudá-lo em movimento no seu desenvolvimento histórico. Essa é a exigência fundamental do método dialético" (1995, p. 67). Nesse sentido, o autor reforça 
que ao abranger, no estudo de um fenômeno, as suas fases e mudanças, o pesquisador pode conhecer sua essência, uma vez que o mesmo se manifesta somente quando em movimento.

Sobre o contexto da pesquisa, ela foi desenvolvida na cidade de São Mateus, situada na região norte do estado do Espírito Santo, em uma escola pública estadual, localizada na área urbana do município. A unidade de ensino possui estrutura física acessivel e de boa qualidade, com salas temáticas, laboratórios de química e biologia, matemática e física e de informática, refeitório, biblioteca, quadra coberta etc. Atende as modalidades de ensino fundamental (séries finais) e ensino médio, em tempo integral.

A pesquisa foi submetida ao Comitê de Ética em Pesquisa (CEP) do Centro Universitário Norte do Espírito Santo (CEUNES), da Universidade Federal do Espírito Santo (UFES). A escolha dos participantes levou em consideração os objetivos deste estudo, sendo três estudantes com deficiência intelectual, três responsáveis e/ou familiares e dois professores da disciplina de química. Para este recorte da dissertação em que discutimos a formação de professores, nos reduziremos a análise e discussão dos resultados dos dados coletados na entrevista semiestruturada com os dois professores. Para preservar a identidade dos profissionais, optamos por utilizar nomes fictícios.

A professora Prata, é professora de química, efetiva da rede estadual na disciplina. Graduada em Licenciatura em Química, mestre em Ensino na Educação Básica. Trabalha desde 2015 como professora de química no ensino médio. Iniciou seu trabalho na escola, onde a pesquisa foi realizada, no ano de 2018. O professor Carbono, é professor de química, efetivo da rede estadual na disciplina. É graduado em Farmácia, com complementação pedagógica em Química. Trabalha desde 2010 como professor de química no ensino médio. Iniciou seu trabalho na escola onde a pesquisa foi realizada no ano de 2019.

O procedimento de coleta de dados na forma de entrevista semiestruturada, aconteceu na escola, em data previamente agendada, com cada professor, durante o horário do planejamento do docente e durou aproximadamente 30 minutos. As respostas obtidas foram gravadas, utilizando-se um aplicativo de gravador no celular e, posteriormente, transcritas na integra, utilizando o Google Docs (voz).

Levando-se em consideração a natureza da pesquisa e os objetivos almejados, optamos por utilizar a técnica de análise de conteúdo, a partir da qual se estrutura a discussão dos resultados. A análise de conteúdo, de acordo com Minayo, Deslandes e Gomes (1994), é a expressão mais comumente usada para representar o tratamento dos dados de uma pesquisa qualitativa.

\section{Análise e discussão dos resultados}

Com base na conceituação de Bardin (1977), organizamos a análise dos resultados da dissertação em três fases: pré-análise, exploração do material e tratamento dos resultados. Nessa perspectiva, as categorias que surgem mediante este processo de análise dos dados obtidos e as unidades de registro, a partir das entrevistas semiestruturadas e observações em sala de aula, justificam a categorização a seguir. A primeira categoria de análise, identificamos como "O ser histórico cultural sob o olhar da família". A segunda categoria de análise, apresentamos como "O (a) estudante e as práticas pedagógicas no ensino de química no contexto da sala de aula". A terceira categoria de análise, nomeamos como "O (a) estudante e a sala de aula na proposta curricular de química sob o olhar dos professores de química".

Para este recorte da dissertação, optamos por apresentar e discutir apenas a categoria "O (a) estudante e a sala de aula na proposta curricular de química sob o olhar dos professores de química", com base nos resultados e discussões dos dados, a partir da entrevista semiestruturada com os dois profissionais. Na discussão da categoria de análise mencionada, procuramos compreender o olhar dos professores Prata e Carbono quanto ao processo de aprendizagem da estudante com deficiência intelectual na disciplina de química e como eles desenvolvem sua ação docente dentro de uma perspectiva inclusiva. 


\section{O(a) estudante com deficiência}

intelectual e a sala de aula na proposta curricular de química sob o olhar da

\section{Professora Prata}

Considerando que os espaços de formação continuada contribuem para a autorreflexão da prática pedagógica do professor e podem conduzir a um processo de mudança, perguntamos a professora Prata se ela participou de cursos de formação continuada na área da educação especial nos últimos anos. Ela nos disse,

Não participei de nenhuma formação na área da educação especial ofertada pela Secretaria de Estado da Educação (SEDU). Apenas de formações do modelo de tempo integral e do novo Currículo do Ensino Fundamental - Anos Finais. Especificamente na área da deficiência intelectual, nunca participei de nenhum (Professora Prata, informação verbal). ${ }^{2}$

Sobre o olhar da professora Prata, quanto a perspectiva da educação inclusiva nas aulas de química, ela afirmou que

Sou a favor da inclusão desde a graduação, pois sabia que isso é algo que temos que abraçar. Até para o aluno que não é deficiente eu levo nas minhas aulas o seguinte: esquece um pouquinho a química. Até mesmo porque eles não sairão daqui químicos formados. Então, da mesma forma que o estudante com deficiência está na sala de aula, estão os outros. Acho muito importante o social. Então acredito que é muito importante para eles, estarem na sala de aula (Professora Prata, informação verbal). ${ }^{3}$

A partir da narrativa da professora, notamos que a formação de professores voltada para o campo da deficiência ainda é um ponto de atenção para nossa realidade educacional. Embora ela tenha a compreensão da importância do social para o desenvolvimento dos estudantes com deficiência, isso não se aplica a muitos professores, o que compromete a inclusão dos estudantes com deficiência. Conforme destaca Mantoan (2003, p. 60), é fundamental "formar, aprimorar continuamente e valorizar o professor, para que tenha condições e estimulos para ensinar a turma toda, sem exclusões e exceções".

Sobre a responsabilidade em assegurar a formação de profissionais da educação, nesta perspectiva inclusiva, a Política Nacional de Educação Especial (BRASIL, 2008) vem reiterar o dever dos sistemas de ensino de garantir a formação de professores para o atendimento educacional especializado e demais profissionais da educação para a inclusão escolar.

Importante ressaltar que a formação docente não se constitui como a solução para todas as indagações em torno do processo de inclusão escolar, já que nos deparamos com outros desafios nas escolas, como estruturas fisicas precárias, número alto de estudantes por sala, plano de carreiras sucateados, dentre outros. Contudo, uma formação bem articulada contribui para que os professores desenvolvam suas práticas pedagógicas, respeitando a diversidade encontrada no contexto da sala de aula e assegurando a todos os estudantes os direitos de aprendizagem.

A cerca do processo de aprendizagem da estudante com deficiência intelectual na disciplina de quimica, a professora relata um episódio que the marcou para exemplificar como procura contribuir com a estudante:

\begin{abstract}
É importante ensinar coisas que façam sentido para os alunos. A obrigatoriedade de fazer com que eles aprendam química é uma grande dificuldade. Por exemplo, eu estava falando sobre mudança de estado físico, dei uma atividade para ela. Expliquei sobre a modificação do estado da água para o sólido, onde a água vira gelo em uma dada temperatura. E perguntei para a estudante se ela já tinha enchido uma forminha para colocar no congelador. Ela me respondeu que nunca havia feito isso. Então eles precisam ter estas experiências na escola e serem estimulados para vivê-las fora da escola também (Professora Prata, informação verbal). ${ }^{4}$
\end{abstract}

Quando perguntamos a professora Prata sobre como ela planeja suas aulas e quais suas principais estratégias metodológicas para trabalhar o currículo da disciplina, ela nos relatou que:

\footnotetext{
2 Depoimento da Professora Prata concedido à pesquisadora Bruna de Oliveira Bonomo, na cidade São Mateus, ES, Brasil, em 16 de dezembro de 2019.

3 Depoimento da Professora Prata concedido à pesquisadora Bruna de Oliveira Bonomo, na cidade São Mateus, ES, Brasil, em 16 de dezembro de 2019

4 Depoimento da Professora Prata concedido à pesquisadora Bruna de Oliveira Bonomo, na cidade São Mateus, ES, Brasil, em 16 de dezembro de 2019 .
} 
Quando eu penso em dar uma aula para uma sala que possui estudante com deficiência, eu penso no geral. Então isso é difícil. Mas eu penso em recursos que facilitam a aprendizagem, como uso de imagens (tecnologias), seminários, práticas experimentais, etc. Eu faço atividades específicas para a estudante com deficiência intelectual sim, mas no momento da minha aula eu procuro atingir a todos porque naquele momento eu sou de todo mundo (Professora Prata, informação verbal). ${ }^{5}$

A partir das narrativas da professora quanto a percepção da aprendizagem de sua disciplina, podemos observar que embora ela não tenha participado de formações específicas para a atuação com estudantes com deficiência intelectual, há um trabalho pedagógico inclusivo desenvolvido na escola que possibilita a atuação docente que esteja pautada na perspectiva inclusiva, aliada à sua formação acadêmica.

Percebemos isso, a partir do acolhimento da estudante com deficiência intelectual e a sua participação nas propostas desenvolvidas nas aulas de química.

A professora se articula por meio do trabalho colaborativo com a professora de atendimento educacional especializado, almejando as adequações curriculares da disciplina para a estudante, elaboração das atividades e avaliações de química com associação de imagens, questões mais curtas e objetivas, exemplos do cotidiano etc., considerando o seu ciclo de alfabetização.

As dificuldades encontradas pela estudante quanto a compreensão dos conteúdos de química é reconhecida pela professora, porém não são entendidas como fatores limitantes do seu processo de aprendizagem e são utilizados a favor e não como barreira. Bastos e Mól (2019) defendem que a compreensão do aluno com deficiência deve ser construida a partir do modo que o sujeito interage, das estratégias que utiliza, daquilo que ele faz, que ele entende e não olhando para aquilo que ele não faz, que não consegue. Enfim, é preciso superar uma visão negativa do sujeito que se constrói a partir do déficit. Focar na eficiência da pessoa e não na sua deficiência.

\section{O(a) estudante com deficiência}

intelectual e a sala de aula na proposta curricular de química sob o olhar do Professor Carbono

Em seguida, procuramos compreender o olhar do Professor Carbono, quanto a sua percepção quanto ao processo de aprendizagem dos dois estudantes com deficiência intelectual da escola e como ele planeja e desenvolve sua ação docente dentro de uma perspectiva inclusiva.

Conforme relato do profissional, ao longo dos anos de docência o mesmo teve experiência, além da deficiência intelectual com estudantes com transtorno espectro autista, a sindrome de Down, hidrocefalia, surdez, dentre outras. 0 professor, reforçou sua dificuldade em sala de aula afirmando a necessidade de formação na área, afirmando que:

A Quimica é uma disciplina muito abstrata.
Então, já temos dificuldade de aprendizagem
dos conteúdos da disciplina pelos estudantes
'ditos normais', para eles que tem a deficiência
é muito mais complicado. Eacaba que ficamos
de mãos atadas, porque não temos formação
especíica para trabalhar com eles e nem um
tempo especíico com eles para realizar este
trabalho que precisam. E também não quere-
mos deixá-los "largados" (Professor Carbono,
informação verbal).

Quando questionado sobre sua participação em formação na área da educação especial, o professor nos disse:

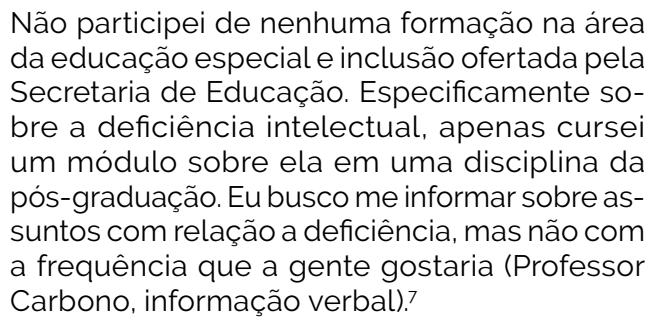

Não participei de nenhuma formação na área da educação especial e inclusão ofertada pela Secretaria de Educação. Especificamente sobre a deficiência intelectual, apenas curse um módulo sobre ela em uma disciplina da pós-graduação. Eu busco me informar sobre asCarbono, informação verbal)? 
Para que os docentes pudessem ser capazes de desenvolver uma educação inclusiva, o curso de formação inicial de professores precisa estar inteiramente voltado para práticas que acompanham a evolução das ciências da educação e que não excluem qualquer aluno. O conhecimento teórico dos avanços científicos em educação é fundamental para que esses professores possam inovar a maneira de ensinar alunos com e sem deficiência nas salas de aula de ensino regular (BRASIL, 2006).

Entendemos que, embora a falta de formação especíica seja um dos pontos de atenção que afeta o trabalho do professor com os estudantes com deficiência, precisamos romper com a ideia de que para estes estudantes se faz necessário oferecer uma pedagogia menor. O professor deve ser um sujeito em permanente processo de formação, que se constitui na interação com outros sujeitos e nas práticas educativas. Sendo assim, é desafio para as escolas e para os professores que repensem a escola e repensem seus alunos no que diz respeito às suas aprendizagens e suas diferenças (CRISTOFOLETI; NUNES, 2019).

Para Rodrigues (2017), a formação de professores tem-se constituído nos últimos anos, em uma área de intervenção e de investigação extraordinariamente ativa. De certa forma, tornou-se uma evidência que a melhoria da escola e da educação não pode ser feita sem um investimento capaz, decidido e competente na formação de professores como principais agentes de mudança.

Com relação a inclusão escolar de estudantes com deficiência intelectual no ensino regular, o professor declarou:

Eu acho um pouco deficitário, primeiro porque nós não temos uma preparação e uma formação específica para isso e segundo porque temos turmas muito cheias o que dificulta o trabalho individualizado com estes estudantes. Sinto muita dificuldade para trabalhar com os dois públicos (Professor Carbono, informação verbal). ${ }^{8}$

Rodrigues (2017) reforça a ideia que ensinar todos os alunos e ensiná-los com qualidade é um objetivo que pode e deve ser evocado em todos os momentos da vida profissional e, sobretudo, na formação inicial, de modo a alertar o professor ainda em formação, de que a sua atuação deve ser planejada, concebida e flexibilizada para que todos os alunos possam estar implicados com proveito nos processos de aprendizagem.

Sobre o discurso de insegurança na atuação com o público avo da educação especial, Mól e Silva (2019), defendem que as dificuldades existentes na atuação do docente podem ser minimizadas com a articulação de ações junto ao Atendimento Educacional Especializado (AEE), à Coordenação e Supervisão para melhorar a inclusão dos alunos com deficiência ou transtornos na escola. Essas ações podem promover espaços de formação, compartilhamentos, estudos, e planejamentos colaborativos para o desenvolvimento de aulas investigativas de ciências, que contemplem a todos.

O professor destacou ainda sobre a inclusão escolar que:

\begin{abstract}
Em um dia, sentado no refeitório, resolvi sentar próximo de uma estudante com deficiência intelectual que dou aula e suas colegas e pude interagir e a vê interagir com as outras meninas, usando as mesmas gírias dos jovens, sorrindo, falando sobre si, etc. Na minha cabeça, a gente tem uma visão que eles são coitadinhos. E eles não são coitados. Talvez é a definição do preconceito. Olhamos para a deficiência e temos uma visão, mas na verdade não é da forma que pensamos (Professor Carbono, informação verbal). 9
\end{abstract}

O professor expressa em sua fala, uma questão relevante acerca da visão preconceituosa que ainda existe com os estudantes com deficiência intelectual (DI). Com referência, a esta base negativa e estigmatizante, Santos e Magalhães (2019), defendem a ideia de que a descredibilização da pessoa com DI, vista sob o olhar de anormalidade, encontram o contexto escolar como espaço em que os valores normativos e as expectativas assentadas em bases negativas

\footnotetext{
8 Depoimento do Professor Carbono, concedido à pesquisadora Bruna de Oliveira Bonomo, na cidade São Mateus, ES, Brasil, em 16 de dezembro de 2019.

9 Depoimento do Professor Carbono, concedido à pesquisadora Bruna de Oliveira Bonomo, na cidade São Mateus, ES, Brasil, em 16 de dezembro de 2019.
} 
e estigmatizantes, ainda, presentes em nossa sociedade, expressam-se de forma mais intensa.

Contrariamente à estigmatização de pessoas com deficiência, a perspectiva histórico-cultural que fundamenta esta pesquisa, favorece a compreensão da deficiência como uma das manifestações possiveis no processo de desenvolvimento humano, com diferenças não apenas quantitativas, mas qualitativas em relação ao desenvolvimento considerado típico. Tal perspectiva permite o reconhecimento do sujeito com deficiência como agente em sua própria trajetória e como sujeito cuja conduta é mediada pelas condições históricas e socioculturais concretas (VYGOTSKY, 1997).

Sobre o planejamento das aulas de química e as metodologias utilizadas para favorecer o processo de apropriação dos conteúdos previstos no currículo da sua disciplina, o professor relatou que:

Na minha perspectiva eu planejo pensando em todos, e utilizo metodologias que possam facilitar a aprendizagem e observo que as atividades em grupos, uso de tecnologias como slides com imagens, vídeos e as práticas experimentais no laboratório de química facilitam a aprendizagem, não só dos estudantes com deficiência, quanto os que não possuem deficiência (Professor Carbono, informação verbal). ${ }^{10}$

Podemos perceber que a partir da narrativa do professor de química, quando aponta as metodologias que potencializam a aprendizagem, enriqueceu a elaboração de práticas pedagógicas envolvendo, como sinalizado por Ferri e Hostins (2006, p. 240):

Conhecimentos didáticos para propor estratégias pedagógicas que configurem apoio aos seus alunos nas mais variadas situações de aprendizagens, como de diversas áreas do conhecimento, que the permitirão estabelecer uma relação critica firmemente apoiada na compreensão de que é no contexto das interações sociais, do jogo dialógico e da intersubjetividade que a aprendizagem adquire sentido.

Pletsch e Oliveira (2017), apontam exemplos de estratégias pedagógicas para estudante com deficiência intelectual que dizem respeito a questões materiais e vivências que criam oportunidades de reconhecimento do conceito trabalhado pelo professor, assim como a confecção de recursos didáticos como: mapas conceituais e esquemas explicativos com ilustrações e palavras-chave sobre o assunto abordado, reorganização do tempo e dos critérios a serem exigidos nesse tempo e espaço escolar.

Para Vygotsky (1987, p. 79), a escola desempenha papel fundamental no desenvolvimento dos processos psicológicos superiores. É ali que em situação de sala de aula, com recursos mediacionais adequados para ter acesso ao conhecimento sistematizado, com ajuda explicita do professor e domínio de novos instrumentos de mediação, é lançada para novos domínios que a sua vivência fora da escola dificilmente permitiria.

Fica explicito que, embora encontre dificuldades na elaboração das atividades e avaliações para os estudantes com deficiência, há uma preocupação de assegurar a participação de todos no processo de ensino. Na narrativa a seguir, o professor entrevistado provoca nossa reflexão sobre a importância do envolvimento dos estudantes na organização das aulas de química, de modo que sejam mais produtivas e atrativas para eles, porém nos coloca sobre o desafio da dinâmica da sala de aula, no caso de um estudante com deficiência intelectual, sem consolidar o ciclo de alfabetização:

É muito difícil conciliar os conteúdos de química se ele ainda está em processo de alfabetização. Então, percebo que parece que nas aulas de práticas experimentais é mais fácil a compreensão dele, porque ele participa, pergunta e se envolve. Tem um retorno ali pra mim. Quando eu tenho slides com imagens percebo que facilita também. Mas, para ele as práticas facilitam mais (Professor Carbono, informação verbal). ${ }^{11}$

Duarte (2008, p. 132) aponta que tais alunos necessitam de adaptações no processo de aprendizagem como maior tempo para a realização

\footnotetext{
10 Depoimento do Professor Carbono, concedido à pesquisadora Bruna de Oliveira Bonomo, na cidade São Mateus, ES, Brasil, em 16 de dezembro de 2019.

11 Depoimento do Professor Carbono, concedido à pesquisadora Bruna de Oliveira Bonomo, na cidade São Mateus, ES, Brasil, em 16 de dezembro de 2019.
} 
das tarefas, ensino individualizado, adaptação curricular e mudança na forma de transmitir os conteúdos e de dosar mais a quantidade das atividades para evitar o cansaço. Podemos visualizar claramente a importância do coletivo no trabalho pedagógico para Padilha quando ela diz que: "É justamente no ambiente coletivo que se dão as relações significativas e promotoras do desenvolvimento" Padilha (2018, p. 68).

A autora completa seu pensamento, afirmando que as pessoas com deficiência intelectual que chegam às escolas o fazem, na verdade, em um meio que está repleto de vivências, que vão determinar o papel de cada situação do meio para o desenvolvimento. Elas começam a fazer parte de um universo cujas condições histórico-culturais estão ou deveriam estar presentes de modo sequenciado, organizado, intencional, metódico. Nessa perspectiva há um objetivo a alcançar que se trata do desenvolvimento das funções psiquicas superiores como o domínio da vontade, atenção voluntária, memória lógica, imaginação, raciocínio, linguagem, leitura, escrita, cálculo, entre outras funções especificamente humanas (PADILHA, 2018).

\section{Considerações finais}

Diante dos resultados obtidos neste trabalho, percebemos que a formação docente não se constitui como a solução para todas as indagações em torno do processo de inclusão escolar, já que nos deparamos com outros desafios, como estruturas físicas precárias, número alto de estudantes por sala, plano de carreiras sucateados, falta de políticas públicas de saúde e assistência social, dentre outros. Contudo, um trabalho educativo bem articulado contribui para que os professores desenvolvam suas práticas pedagógicas, respeitando a diversidade encontrada no contexto da sala de aula e entendendo que todos os estudantes possuem seu direito de aprendizagem.

Fato é, o que se registra como papel fundamental quando se trata da inclusão escolar, que o papel do professor se torna de suma importância, quando ele se reconhece como um mediador de todas as situações de aprendizagem para que o estudante receba o conhecimento em qualquer área do saber e amplie sua visão de mundo. Nesse sentido, entendemos que a aprendizagem é influenciada pela formação docente, já que está atrelada à metodologia utilizada pelos professores em suas aulas.

Notamos que embora os dois professores não possuam formação especifica no campo da deficiência intelectual e outras deficiências, que o trabalho deles se fundamenta em envolver esses sujeitos na dinâmica de suas aulas. Esse compromisso potencializa os resultados desta pesquisa, pois percebemos que se trata de uma escola que se sensibiliza com a perspectiva de uma educação inclusiva e que os professores se preocupam com as particularidades de seus estudantes.

Isso posto, nos faz refletir que para que a inclusão ocorra em nossas escolas, não é necessário a disseminação de práticas pedagógicas mirabolantes, embora a utilização de recursos didáticos, sejam necessários e essenciais, a sua indisponibilidade não deve se tornar como um desafio que inviabilize o direito a aprendizagem de forma equânime. Para tal, é inegável a relevância da formação docente nesta construção. A socialização de práticas exitosas dentro da escola, também fortalecem este espaço como um ambiente em potencial para a formação continuada. Certamente há muito para avançar nesse assunto. Contudo, cada pequena conquista precisa ser celebrada e compartilhada para que haja replicabilidade entre os professores e se consolidem como caminhos de avanços na educação inclusiva.

\section{Referências}

ANDRÉ, Marli Eliza Dalmazo Afonso de. O que é um estudo de caso qualitativo em educação? Revista da FAEEBA - Educação e Contemporaneidade, Salvador, v. 22, n. 40, p. 95-103, jul./dez. 2013. Disponivel em: https://revistas.uneb.br/index .php/faeeba/article/ view/8267. Acesso em: 10 out. 2020. 
BARDIN, Laurence. Análise de conteúdo. Lisboa: 70, 1977.

BASTOS, Amélia Rota Borges de. MÓL, Gerson. Desenvolvimento de práticas inclusivas: aportes teórico- práticos para o apoio aos estudantes em estágio de docência. In: MÓL, Gerson (org.). O ensino de Ciências na escola inclusiva. Campos dos Goytacazes, RJ: Brasil Multicultural, 2019.

BERNI, Regiane Ibanhez Gimenes. Mediação: o conceito vygotskyano e suas implicações na prática pedagógica. São Paulo: LAEL /PUC - SP. 2006. Disponivel em: http://www.filologia.org.br/ileel/artigos/artigo_334. pdf. Acesso em: 15 nov. 2019.

BITENCOURT, T. V. DE; ARAÚJO, A. P. Inclusão escolare ressignificação da formação docente: possibilidades e desafios a partir das contribuições de Gadamer.

Educação Por Escrito, Porto Alegre, v. 5, n. 1, p. 41-50, 26 jun. 2014.

BRASIL. Instituto Nacional De Estudos E Pesquisas Educacionais Anísio Teixeira. Resumo Técnico do Estado do Espírito Santo: Censo da Educação Básica Estadual 2019. Brasilia, DF: 2020.

BRASIL. Ministério da Educação. Secretaria de Educação Especial. Deficiência a mental - (Atendimento Educacional Especializado). Brasilia: MEC/SEESP, 2007.

BRASIL. Secretaria de Educação Especial. Educação Inclusiva. Brasilia, DF: MEC/SEESP, 2006. Disponivel em: http://portal.mec.gov.br/seesp/arquivos/pdf/ defmental.pdf. Acesso em: 28 abr. 2020.

BRASIL. Convenção sobre os Direitos das Pessoas com Deficiência comentada. Brasília: CORDE, 2008

BRASIL. Instituto Nacional De Estudos E Pesquisas Educacionais Anísio Teixeira. Censo da Educação Básica 2019. Brasilia, DF: INEP. Disponivel em: http://portal. inep. gov.br/censo-escolar. Acesso em: 10 abr. 2020.

CRISTOFOLETI, Rita de Cassia; NUNES, Isabel Matos. A prática Pedagógica e a deficiência intelectual: produção de recursos didáticos. In: PEROVANO, Laís Perpetuo MELO, Douglas Christian Ferrari de (org.). Saberes, estratégias e recursos didáticos. Rio de Janeiro: Brasil Multicultural, 2019. p. 37-51.

CUNHA, Antônio Eugênio. Práticas Pedagógicas para a inclusão e diversidade. 2 ed. Rio de Janeiro: Wark Editora, 2012

CURY, Carlos Roberto Jamil. Educação inclusiva como direito. In: SEMINÁRIO NACIONAL DE EDUCAÇÃO ESPECIAL, 3.; SEMINÁRIO CAPIXABA DE EDUCAÇÃO INCLUSIVA, 14., 2014, Vitória. Anais [...]. Vitória: UFES, 2014. v. 1. p. $1-15$

DUARTE, Márcia. Síndrome de Down: situação escolar no ensino fundamental e médio da cidade de Araraquara-São Paulo. Orientadora: Professora Dra. Luci Pastor Manzoli. 2008. 83 f. Tese (Doutorado em Letras) - Faculdade de Ciências e Letras de Araraquara. São Paulo: UNESP, 2008. Disponivel em: http://wwws. fclar.unesp .br/agenda-pos/educacao_escolar/1404. pdf. Acesso em: 4 fev. 2020
FRANCO, Maria Amélia do Rosário Santoro. Pedagogia e prática docente. 1. ed. São Paulo: Cortez, 2012.

FERRI, Cássia; HOSTINS, Regina Célia Linhares. Práticas de seleção e organização do Conhecimento de escolas regulares e especiais. Revista Educação e Realidade, Rio Grande do Sul, v. 33, n. 2, p. 22, jul./ dez. 2008. ISSN 2175-6236. Disponivel em: https:// seer.ufrgs.br/educacaoerealidade/article/view/7074. Acesso em: 10 jan. 2021

LIBÂNEO, José Carlos. Didática. São Paulo: Cortez, 1994.

MALDANER, Otavio Aloisio. A formação inicial de professores de química professor pesquisador. 3 . ed. ljui: Unijuí, 2006

MALHEIROS, Bruno Taranto. Metodologia da Pesquisa em educação. Rio de Janeiro: LTC, 2011.

MANTOAN, Maria Teresa Egler. Inclusão Escolar: o que é? Por quê? Como fazer? 1. ed. São Paulo: Moderna, 2003

MINAYO, Maria Cecilia de Souza; DESLANDES, Suely Ferreira; GOMES, Romeu. Pesquisa social: Teoria, Método e Criatividade. Petrópolis: Vozes, 1994.

MÓL, Gerson de Souza. SILVA, Keilla Christina Desidério. Professores regentes de Ciências da Natureza na sala de aula inclusiva. In: MÓL, Gerson (org.). O ensino de Ciências na Escola Inclusiva. Campos dos Goytacazes, RJ: Brasil Multicultural, 2019. p. 117-131.

PADILHA, Anna Maria Lunardi. Alunos com deficiência intelectual: reflexões sobre o conceito de desenvolvimento das funções psiquicas superiores e o papel da educação escolar na perspectiva histórico cultural da escola de Lev Vigotski. Horizontes, [S. I.], v. 36, p. 62-73, set./dez. 2018.

PIMENTA, Selma Garrido. Formação de professores - saberes da docência e identidade do professor. São Paulo: Nuances, 1997. v. 3.

PLETSCH, Márcia Denise. OLIVEIRA, Mariana Corrêa Pitanga de. A escolarização de pessoas com deficiência intelectual na contemporaneidade: análise das práticas pedagógicas e dos processos de ensino e aprendizagem. In: CAIADO, Kátia Regina Moreno. BAPTISTA, Cláudio Roberto. JESU, Denise Meyrelles de (org.). Deficiência Mental e Deficiência intelectual em debate. 1. ed. Uberlândia: Navegando Publicações, 2017. p. 265-285.

RODRIGUES, David. Os desafios da Equidade e da Inclusão na Formação de Professores. In: OLIVEIRA, Ivone Martins de; RODRIGUES, David, JESUS, Denise Meyrelles de. Formação de Professores, práticas pedagógicas e inclusão escolar: perspectivas luso-brasileiras. Vitória: EDUFES, 2017. p. 23-47.

SANTOS, Rogério Alves dos. MAGALHHÃES, Rita de Cássia Barbosa Paiva. Vozes de estudantes com deficiência intelectual: construção identitária e estigma. Campos de Goytacazes, RJ: Brasil Multicultural, 2019. 
SECRETARIA DE EDUCAÇÃO DO ESTADO DO ESPIRITO SANTO. Currículo Básico Escola Estadual Ensino Médio: Área de Ciências da Natureza. Vitoria: SEDU, 2009. v. 2. Disponivel em: https://sedu.es.gov.br /Media /sedu/ pdf\%20e\%20Arquivos/Ensino\%20M\%C3\%A9dio\%20 -\%20Volume\%2002\%2 0-\%20Ci\%C3\%AAncias\%20da\%20 Natureza.pdf. Acesso em: 10 nov. 2020

SCHNETZLER, Roseli Pacheco. A Pesquisa no Ensino de química e a Importância da Química Nova na Escola. Química Nova, Piracicaba, n. 20, p. 49-54, 2004. Disponivel em: http://qnesc.sbq.org.br/online/qnesc20/ v20a09.pdf. Acesso em: 20 jan. 2020.

VYGOTSKY, Lev Semenovich. Pensamento e Linguagem. São Paulo: Martins Fontes, 1987.

VYGOTSKY, Lev Semenovich. Tratado de Defectologia Havana: Pueblo Y Educación, 1995. (Obras Completas, t. 5)

VYGOTSKY, Lev Semenovich. Fundamentos de Defectologia. Havana: Editorial Pueblo y Educación, 1997. (Obras completas, t. 5).

\section{Bruna de Oliveira Bonomo}

Mestre em Ensino na Educação Básica pelo Programa de Pós-Graduação em Ensino na Educação Básica da Universidade Federal do Espírito Santo (PPGEEB), em São Mateus, ES, Brasil.

\section{Ana Nery Furlan Mendes}

Doutora em Química pela Universidade Federal do Rio Grande do Sul (UFRGS), em Porto Alegre, RS, Brasil, com periodo sanduíche na Universitat Autónoma de Barcelona (UAB), em Barcelona, Espanha; professora da Universidade Federal do Espírito Santo (UFES), em São Mateus, ES, Brasil.

\section{Endereço para correspondência}

\section{Bruna de Oliveira Bonomo}

Rua Vila Pinha, 108, apto. 101

Centro, 29930-060

São Mateus, ES, Brasil

\section{Ana Nery Furlan Mendes}

Universidade Federal do Espírito Santo

Centro Universitário Norte do Espírito Santo

Departamento de Ciências Naturais

$\mathrm{Br} 101$ Norte, Km 60, Prédio DCN, sala 04

Litorâneo, 29932-540

São Mateus, ES, Brasil
Os textos deste artigo foram revisados pela Poá Comunicação e submetidos para validação das autoras antes da publicação. 